\title{
Sur quoi les autochtones gardent le silence et pourquoi
}

О ЧЕМ И ПОЧЕМУ МОЛЧАТ АБОРИГЕНЫ

About what do natives keep silence and why?

\author{
Natal'ja Novikova
}

Traducteur : Eva Toulouze

\section{(2) OpenEdition}

\section{Journals}

Édition électronique

URL : https://journals.openedition.org/efo/4970

DOI : $10.4000 /$ efo. 4970

ISSN : 2275-1947

Éditeur

INALCO

Édition imprimée

ISBN : 978-2-343-08571-5

ISSN : 0071-2051

Référence électronique

Natal'ja Novikova, «Sur quoi les autochtones gardent le silence et pourquoi », Études finno-ougriennes [En ligne], 47 | 2015, mis en ligne le 13 juillet 2016, consulté le 20 septembre 2021. URL : http:// journals.openedition.org/efo/4970 ; DOI : https://doi.org/10.4000/efo.4970

Ce document a été généré automatiquement le 20 septembre 2021.

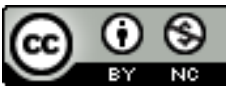

Études finno-ougriennes est mis à disposition selon les termes de la Licence Creative Commons Attribution - Pas d'Utilisation Commerciale 4.0 International. 


\title{
Sur quoi les autochtones gardent le silence et pourquoi
}

\author{
О ЧЕМ И ПОЧЕМУ МОЛЧАТ АБОРИГЕНЫ \\ About what do natives keep silence and why?
}

\author{
Natal'ja Novikova
}

Traduction : Eva Toulouze

\section{NOTE DE L'AUTEUR}

Ce travail a été réalisé dans le cadre du programme de recherches fondamentales du présidium de l'Académie des Sciences de Russie « Les recherches scientifiques fondamentales dans l'intérêt de la zone arctique de la Fédération de Russie » (Projet «Les peuples autochtones et l'exploitation industrielle de l'Arctique : élimination des risques et stratégies de développement »).

1 Dans l'univers des peuples autochtones, la parole et le silence remplissent une fonction de communication. Dans bien des situations importantes, la priorité est même donnée au silence. Le silence se présente comme un marqueur culturel des autochtones, un code central et le moyen de se présenter dans le monde contemporain. Dans les interactions des autochtones avec le monde environnant, le silence est un outil particulier, mais pour le comprendre et être capable de l'interpréter, il faut étudier la culture autochtone et comprendre pourquoi et quand ils parlent ou choisissent de se taire. On peut comparer le silence avec le permafrost, le fondement de la sauvegarde de la nature arctique. Or dans la perception des représentants des autres cultures, le silence ou le manque de communication orale des autochtones est souvent reçu comme un défaut. 


\section{Le droit à la parole et au silence}

2 La parole et le silence sont des traits caractéristiques indissociables de l'univers des autochtones du Nord. Ceci apparaît de manière particulièrement claire dans leur interaction avec les entreprises industrielles et les organes du pouvoir d'État. C'est bien dans l'intention de donner aux autochtones le droit à la parole dans le système juridique qu'a été adoptée la législation les concernant en Russie. Sans elle, leurs soucis et leurs intérêts relevaient de la sphère du silence de la part des organes de l'État. Ce silence était équivalent à un vide. Il établissait un abîme entre les autochtones et le gouvernement, les hommes et le gouvernement. Les petits peuples autochtones de Russie sont sortis de ce silence en 1993, quand a été adoptée la nouvelle Constitution ; par la suite ont été adoptées des lois qui réglementaient leur position au sein de l'État mais encore aujourd'hui bien des problèmes sont loin d'avoir trouvé une solution. Dans cet article, je veux m'arrêter uniquement sur un aspect de l'anthropologie du silence, dans le contexte de la politique de l'État, dans ses liens avec la pratique judiciaire. La parole dite ou écrite est acceptée en tant que norme d'une réglementation rigide, et souvent elle ne correspond guère aux mécanismes de transmission de l'information en œuvre dans les sociétés traditionnelles. Ce sont ces traits culturels qui caractérisent le comportement des autochtones au tribunal, leur impossibilité de parler de telle ou telle chose. Dans les circonstances actuelles, ceci peut tenir à leur inexpérience et à leur analphabétisme juridique. Comme la plupart des gens en Russie, ils souffrent d'un manque de connaissances juridiques et ignorent comment les mettre en œuvre. En même temps, dans la culture des autochtones il existe beaucoup d'interdits, de cas où il n'est pas autorisé par exemple de parler de petits enfants ou de lieux sacrés. L'art. 14 de la loi fédérale "Sur les garanties des droits des petits peuples autochtones de la Fédération de Russie » stipule que

lors de l'examen par les tribunaux des affaires dans lesquelles les personnes ressortissantes des petits peuples se présentent en qualité de demandeurs, de victimes ou d'accusés, les traditions et les coutumes de ces peuples peuvent être prises en considération, si elles ne contredisent pas les lois fédérales et les lois des sujets de la Fédération de Russie. Afin de garantir l'efficacité de la défense judiciaire des droits des petits peuples, la participation de représentants mandatés des dits peuples sera autorisée.

3 Dans ces cas, un anthropologue pourra intervenir en qualité d'expert-médiateur au tribunal, présenter les explications nécessaires, dans la mesure l'essence des silences ne peut être expliquée aux juges que par un spécialiste. Il faut savoir d'ailleurs qu'à la demande des participants au procès, ce dernier peut, dans des cas particuliers, être tenu à huis clos ; il est toujours possible de demander à bénéficier de ce droit.

Il est vrai que le nombre de procès de ce type a été jusqu'ici relativement faible. Leur analyse montre que les particularités du mode de vie traditionnel, de la vision du monde autochtone s'avèrent être un obstacle à l'obtention d'une décision juste, dans la mesure où tout simplement les juges ne les comprennent pas. Les différences dans les manières de communiquer des participants à ces procès présentent des difficultés supplémentaires, mais elles sont indissociables de la culture normative et doivent devenir objet d'étude non seulement pour les anthropologues, mais aussi pour les juristes.

5 Le droit international est plus sensible aux particularités de la communication dans la culture des peuples autochtones. Le silence y est vu comme partie intégrante de leur 
univers. C'est en 1992 qu'a été adoptée la convention de l'ONU sur la biodiversité, qui prévoit l'obligation pour les États membres de préserver et de soutenir les connaissances et les pratiques traditionnelles des peuples autochtones qui sont pertinentes pour maintenir la diversité biologique. La conférence ayant travaillé à cette convention a débouché sur "Akwe-kon: Lignes directrices facultatives pour la conduite d'études sur les impacts culturels, environnementaux et sociaux des projets d'aménagement ou des aménagements susceptibles d'avoir un impact sur des sites sacrés et sur des terres ou des eaux occupées ou utilisées traditionnellement par des communautés autochtones locales ». Dans ce document, l'évaluation des spécificités culturelles repose entre autres sur la conformité avec le respect de l'intimité culturelle, ce qui peut être interprété comme le droit au silence.

6 La stabilité des frontières communicatives est l'une des raisons qui expliquent que les peuples autochtones souvent n'acceptent pas les lois "écrites ", mais continuent à construire leur vie sur les normes du droit coutumier, qui n'est pas réductible à être fixé par écrit. Certaines procédures dans le monde contemporain présentent un intérêt tout particulier : il s'agit des procédures alternatives de résolution des conflits par des moyens non judiciaires, procédures usuelles non seulement pour les communautés autochtones, mais aussi dans certains pays - on peut prendre pour par exemple la justice canadienne à propos de la délinquance juvénile ${ }^{1}$. Le trait principal de la résolution autochtone des conflits est la nécessité d'aboutir à un consensus. L'un des moyens pour y arriver est la plume d'aigle, symbole de la parole dans les cercles rendant la justice en Amérique du Nord et au Canada. Les participants s'expriment en tenant à la main une plume d'aigle, qui passe de main en main dans le sens des aiguilles d'une montre. Le symbole de la parole aide à parler et à écouter, il confère au dialogue un certain rythme et garantit l'égalité à l'intérieur du cercle. Tout autre objet peut servir de symbole de la parole, mais il doit absolument s'agir d'un objet jouissant de respect de la part des participants au cercle, et il doit être porteur d'une charge symbolique (Pranis, Stewart, Wedge 2010). Ainsi, le symbole de la parole finit par devenir l'élément déterminant dans la communication : il réglemente non seulement le droit à la parole, pendant le temps où une personne tient la plume à la main, mais l'obligation pour tous les autres de se taire. Grâce à lui, les gens ne s'interrompent pas, et chacun a la possibilité d'être écouté ; donc, le conflit a des chances d'être résolu.

Des représentations similaires existent aussi chez les autochtones de Sibérie. Dans bien des cas, la laconicité des autochtones du Nord permet également de mieux s'écouter. On trouve une observation intéressante dans une étude d'O.B. Hristoforova sur les cultures samoyèdes :

Quelque importante que soit une personne, elle ne pourra pas parler avant d'avoir l'accord de son interlocuteur: la formule "j'ai la parole» inclut la demande d'écoute, et tant que l'interlocuteur n'a pas prononcé les mots : « quelle que soit ta parole, parle ", rien ne peut être dit. De manière générale, on peut qualifier les cultures samoyèdes de "cultures du silence». Les normes de leur étiquette d'interlocution ne permettent pas l'expression directe d'une demande, d'un refus ou d'une appréciation. La préférence donnée aux formes d'expression non catégoriques, aux métaphores et aux moyens d'expression non verbaux s'explique par l'aspiration à ne pas imposer sa pensée à son interlocuteur, à lui permettre de comprendre ce qui sous-tend le propos et en tirer lui-même les conclusions. En disant quoi que ce soit (indépendamment du code du message), le locuteur espère que le destinataire répondra comme il convient. La personne regarde ses actes avec les yeux de son partenaire; c'est le même type de comportement réflexif et socialement responsable qui est attendu de ce dernier. (Hristoforova 2006) 
Il convient de nous pencher maintenant sur une autre dimension du silence: la frontière culturelle. Bien que mes interlocuteurs aient parfois parlé de la possibilité de "communiquer en silence» avec des porteurs d'autres cultures, ils ont surtout souligné le rôle central du silence dans la leur. Dans un entretien avec le peintre G.S. Rajšev, j'ai noté son avis sur les différents types de silence :

Le peuple a une culture du silence : ne pas dire des paroles superflues et inutiles, mais plutôt écouter, et se positionner souvent non pas par des mots, mais par son comportement, son attitude. On rencontre quelqu'un, disons : on est tendu, mais avec l'autre il n'y a pas de tension; la culture de la confiance ne va pas s'établir par des paroles, mais par le silence ; rester en silence avec la personne est dans ce cas possible. Mais la rencontre avec quelqu'un d'autre peut provoquer un déséquilibre psychologique. Si tu ne dis rien, tu dois réfléchir. Il existe un silence agressif. C'est une tactique des fonctionnaires, ce n'est pas par hasard. Avec ce silence, ils semblent bétonner l'espace. La personne en face d'eux se met à hésiter. C'est une manière d'agir sur le demandeur. Des gens pareils, je les licencierais aussitôt. (Notes de terrain, 2001, Hanty-Mansijsk)

9 Le silence des autorités a d'autres buts, les frontières qu'il suscite restent indéterminées. Les industriels du pétrole, eux aussi, utilisent le silence pour fermer, pour créer une subculture verrouillée. Par exemple, ils présentent telle ou telle information comme un secret commercial, pour cacher leur intention d'arracher une terre à l'exploitation autochtone traditionnelle. Dans ces cas, le silence sert à dissimuler, il représente une absence de communication, et le conflit ne peut plus être résolu que par les moyens officiels, par une cour de justice.

\section{Ton silence est malhonnête}

10 Dans les travaux ethnographiques, le silence est étudié la plupart du temps comme un interdit sur la parole, comme une manifestation de l'autre. De nouveaux matériaux de terrain permettent de regarder cette question de manière différente et de montrer le rôle du silence en tant que moyen de communication. Car c'est bien cette fonction qui, dans le droit coutumier autochtone, est déterminante. C'est ce qu'illustre bien la formule utilisée par les autochtones entre eux: "Tu te tais de façon malhonnête", « ton silence est malhonnête ».

11 Il y a des choses sur lesquelles on n'a pas le droit de s'exprimer, alors qu'on peut transmettre l'information en utilisant des objets. Les autochtones font davantage confiance à des moyens non verbaux de communication, par exemple, les entailles sur des plaques. Ainsi lors de l'une des fêtes les plus importantes des Ougriens de l'ob, les jeux de l'ours, le nombre des chants exécutés ou des saynètes jouées est inscrit par des entailles sur une baguette spéciale ou un bâton spécial. À cela il faut ajouter que des représentations différentes de par le sens et le statut sont notées avec un nombre d'entailles différent. Ces dernières, à leur tour, venaient ajouter du sens au chant ou à la représentation.

12 Quand les Khantys, aujourd'hui, se rassemblent pour de grandes cérémonies sacrificielles, ils en informent toujours leurs voisins et parents à l'aide d'une baguette entaillée. Ils font passer ou montrent cette baguette, qui permet de savoir quand et où la cérémonie aurait lieu. En 1931, c'est à l'aide d'un objet de ce genre que se rassemblèrent les participants à la guerre du Kazym. Cette baguette était appelée šumty-juh, elle était transmise de village en village et revenait à l'expéditeur, avec les signes 
claniques de tous ceux qui avaient annoncé leur participation au rassemblement (Golovnëv 1995, p. 167-168). Il est intéressant de noter que des supports de messages pareils étaient utilisés dans les années 1920-30 dans les tribunaux autochtones dans le nord de la Russie, lorsque le pouvoir soviétique s'efforçait de partir des normes du droit coutumier de ces peuples pour construire un système judiciaire ${ }^{2}$.

Dans la littérature scientifique, les moyens de communication non verbaux sont présentés la plupart du temps en rapport avec le langage des gestes (par exemple, Butovskaja 2004; Krejndlin 2005). Chez les autochtones du nord, les gestes sont relativement rares, sur ce plan leur culture est plutôt laconique. Ce sont les actes plus que des gestes en tant que tels qui sont mis en œuvre. Par exemple, une invitation à entrer et à s'asseoir dans la tente est un moyen largement employé pour engager la communication. Ils transportent des tentes jusqu'à Moscou pour les monter sur une place du Centre d'expositions, et font de même lors des Journées des éleveurs de rennes dans les villages et dans les villes du Nord. Les autochtones estiment que pour des gens d'une autre culture, il est assez simple de passer un moment dans un čum ${ }^{3}$, de boire du thé et de manger quelque chose ; ainsi peuvent-ils ressentir quelque chose de la culture des peuples du Nord, et, en fin de compte, le contact deviendra plus facile. C'est peutêtre pour cette raison qu'au début des années 2000, le čum a été largement utilisé dans la compagne électorale dans l'okroug autonome de Hanty-Mansijsk.

14 L'interaction des autochtones avec les travailleurs des compagnies pétrolières prend surtout la forme de contacts d'affaires - signatures d'accords économiques, rencontres dans le cas de conflits ; c'est pourquoi il est pertinent de présenter ici les observations faites par des psychologues de pays divers, qui ont noté que l'effet sur les autres au cours de contacts professionnels oraux ne dépend que pour approximativement $7 \%$ de ce que nous disons, pour $38 \%$ de la manière dont nous parlons, et pour $55 \%$ de notre langage corporel. Il a également été calculé que $80 \%$, voire parfois $90 \%$ de toute la dimension émotionnelle a été exprimée avant de commencer à parler et passe dans la communication d'affaires interactive par des moyens non verbaux (Krejndlin 2005, p. 152).

15 En étudiant les peuples autochtones, et surtout leurs rapports avec les compagnies pétrolières et les organes du pouvoir d'État, il est particulièrement important de réfléchir sur les fondements des limites mises à l'usage de la parole et d'en montrer le contexte culturel. O.B. Hristoforova a étudié les particularités du comportement des Nénetses comme une source possible de conflits et de problèmes dans les relations professionnelles avec les spécialistes divers, arrivés dans le nord d'autres régions et adoptant le système de communication que les gens du Nord associent avec les Russes. La même tension caractérise les relations de la population autochtone avec les autorités locales, les organisations commerciales ou étatiques. D'après elle, ce phénomène tient pour beaucoup

aux spécificités ethnoculturelles des normes du comportement communicationnel des Russes et des autochtones, autrement dit, à la non-correspondance du comportement considéré comme juste dans la communication.

D'ailleurs, le rapport des autochtones à la parole est bien illustré dans leurs proverbes :

La parole, c'est comme un couteau sans manche, il faut faire très attention » (proverbe nganassane);

De même qu'un renne a peur des loups, ainsi les gens ont peur des bavards (proverbe nenetse), 
à mettre en rapport avec des proverbes iakoutes :

Moins de mots, c'est bon ; beaucoup de mots, c'est amer ;

La parole humaine, c'est comme une hache ;

Plus on dit de mots, plus on fait d'erreurs ;

Toute parole dite est entendue (cité d'après Hristoforova 1998, p. 224-231).

\section{De quoi ne parle-t-on pas?}

18 À côté de la culture de la parole, les autochtones ont aussi une culture du silence. Et ce qui fait l'objet du silence ainsi que la manière dont il est pratiqué dans les campements peut en dire long sur la manière dont ils établissent la communication entre les cultures. Le plus important est le fait que le silence fonctionne non seulement au sein de la communauté, mais dans la communication interculturelle. À l'heure actuelle, la valeur du silence dans ces conditions est de plus en plus signifiante et prégnante, dans la mesure où les autochtones sont de plus en plus intégrés dans la vie qui environne leur communauté. On peut dire que le silence est une partie de leur connaissance du monde environnant et qu'il peut de ce fait être considéré comment une composante majeure de leur identité et de leur statut au sein de l'État.

Les interdits portant sur des mots, sur des propos, sur les noms des animaux, reposent sur les représentations de certains peuples du Nord d'après lesquelles les paroles et les pensées existent dans le réel. Chez les Dolganes, par exemple, d'après les données de A.A. Popov, «tout chasseur, en train de guetter les rennes sauvages avec son fusil, naturellement pensait à la manière d'attraper des rennes, c'est-à-dire, d'après sa vision des choses, ce chasseur était investi de l'ombre des rennes, qui étaient en rapport avec leur essence matérielle. Ces formes-ombres, ressortant par la bouche du chasseur, étaient susceptibles de prévenir les rennes et de les conduire sur un autre chemin. Pour éviter ceci, le chasseur se bouchait la bouche avec une touffe d'herbe... Par ailleurs, chez les Inuits du cuivre il existait un interdit sur les danses et les chants en dehors du domicile, à ciel ouvert, car dans ces conditions les paroles du chant pouvaient «se répandre » dans toutes les directions, et le chanteur risquait de mourir (Popov 1959, p. 89 ; Jenness 1923, p. 184 ; d'après Ivanov 1975). Dans son analyse des éléments mentionnés ci-dessus et de bien d'autres chez différents peuples, S.V. Ivanov conclut que dans ces cas les paroles se voyaient attribuer la capacité de se transformer en animaux visibles et en êtres fantastiques (Ivanov 1975). Bien sûr, les tabous sur des mots, les limitations des propos dans certaines circonstances existent chez tous les peuples. Le rôle important du mot dans la culture des autochtones tient à ce qu'il est vu comme porteur de force vitale, d'énergie. C'est le cas chez les Nénetses. E.T. Puškarëva, spécialiste d'oralité nénetse, note que les formes de la parole sont caractérisées par « la transmission au héros d'énergie vitale aussi bien par leur sonorité que par leur vibration » (Puškarëva 2002 ; 2007, p. 35-36).

Il existe différents types de silence. Il y a des choses dont on n'a pas le droit de parler : la parole peut détruire aussi bien l'objet sacré que le lien que l'on entretient avec lui. Ce sont des normes qui touchent principalement au domaine du sacré. De nombreux militants et chercheurs autochtones estiment qu'il ne faut même pas poser de questions sur ce genre de sujet.

Les légendes sacrées sont tabou. Elles ne se racontent que dans des cas précis, par une personne précise à quelqu'un à qui elle fait confiance, qui par la même occasion se voir transmettre des instructions précises sur ce qu'il doit faire des informations 
reçues. Il faut toujours le garder à l'esprit. La manière la plus sûre de perdre toute confiance auprès des Ougriens de l'Ob, c'est de leur demander de vous parler des « légendes sacrées » (Pesikova 2000, p.133). droit de parler dans certaines situations, par exemple avant la chasse, ou le soir. Il existe des normes encore plus sévères à propos du comportement dans la forêt, où il ne faut pas troubler la tranquillité - le calme des esprits. Le silence jour un rôle important également dans la vie quotidienne des autochtones: il existe une multitude de règles, surtout en rapport avec les principales dimensions de la vie. Par exemple, il ne faut pas parler des enfants avant qu'ils aient un an, car ces enfants sont encore à la frontière entre le monde des hommes et celui des esprits. Il ne faut pas non plus parler des résultats de la chasse ou de la pêche. Plusieurs informateurs m'ont raconté qu'ils ont assimilé cette règle depuis leur enfance : quand un chasseur revient de la chasse, il ne faut rien lui demander (voir aussi Lapina 1998, p. 29). De toute manière, il vaut mieux ne pas parler du tout de la chasse puisque, d'après les représentations des chasseurs, les bêtes peuvent écouter. Il existe une règle, d'après laquelle il ne faut pas parler des réussites futures. Il existe même une saynète à ce sujet dans les jeux de l'ours. En 1981, j'ai assisté à une de ces représentations au village de V. Nild'ino dans l'okrug autonome de Hanty-Mansijsk. La saynète était accompagnée de chants et de musique instrumentale jouée sur l'instrument à cordes sangultap. En voici le contenu :

C'est la nuit, le vieil élan dort et en rêve il entend: « Demain à midi viendront les chasseurs, ils vont vous poursuivre ». Il dit au jeune élan : « Toi, les chasseurs vont te tuer, mais moi, je franchirai l'Oural ». Le matin, les rennes courent. Le jeune élan les entend, les chasseurs sont tout près, ils ne vont pas tarder à le rattraper. Le jeune élan est léger, il court très vite, il dépasse tout le monde et il s'enfuit. Soudain, il entend un coup de feu : ils avaient tué le vieux chef élan.

En m'expliquant la chanson, son interprète me dit que l'histoire se terminait ainsi parce que le vieil élan avait parlé à l'avance : «il ne faut jamais rien dire à l'avance, surtout avant une chasse ».

Dans ce cas, ce tabou cynégétique a été transposé dans le monde des animaux (Novikova 1995, p. 145). Les jeux de l'ours des Ougriens de l'ob' n'était pas seulement leur fête principale, un ensemble de rituels d'une importance vitale : il remplissait aussi la fonction de transmission de la tradition, des connaissances, des normes aux générations suivantes.

Dans la vie quotidienne, l'exigence de silence est dictée par les conditions de vie - vivre dans un campement ou dans un čum où les gens sont nombreux appelle le respect de ces normes. Mais pour les autochtones, il y a une différence entre le silence pour cacher une information importante et le silence quotidien qui frappent les personnes extérieures qui arrivent pour la première fois dans un campement. Un dicton est significatif : "on ne compte ni les enfants ni les rennes». Ce n'est pas la peine de demander combien telle ou telle famille a de rennes - pour ne pas mettre les gens dans une situation où ils doivent enfreindre une norme. Ainsi, le silence, dans un espace domestiqué, connu, est réglementé par des normes qui ne dépendent pas seulement de l'espace lui-même, mais aussi du moment - les interdits sont particulièrement nombreux le soir. 
Dans les campements, les gens ne se hâtent pas de raconter tout ce qu'ils savent ou tout ce qu'ils ont vu. Parfois, quelqu'un qui rentre chez lui avec ses rennes dit deux ou trois mots, et tout le monde dans la maison sait quel chemin il a pris, où il a passé la nuit, ce qu'il a vu sur le chemin. A.S. Pesikova appelle ce trait de leur culture «l'ouverture fermée ». Elle écrit :

Parmi les Khantys du Pim on rencontrera souvent des personnes ouvertes, tellement qu'elles en semblent naïves. Mais c'est une seulement une apparence d'ouverture. L'expérience historique de préservation de l'identité a dicté aux Ougriens de l'ob cette tactique : tout ce qui est intime, sacré doit être gardé loin des étrangers, loin de ce qui est mauvais. Les Khantys du Pim sont toujours hospitaliers : ils vous nourriront, vous accueilleront pour la nuit; mais ils ne vous raconteront pas tout, ils ne vous montreront pas tout (Pesikova 1996b, p. 230).

\section{Le silence comme protestation}

Dans les conditions actuelles, le silence peut être également une forme de protestation sociale. Par exemple dans les régions à gisements de pétrole, qui se trouvent juste à côté des territoires habités par des Khantys, il m'est arrivé de rencontrer des adolescents et même de jeunes adultes qui ne savent pas du tout le russe. Malheureusement, dans ces contrées, beaucoup de Khantys ne voient aucun avenir pour eux et estiment que cela ne vaut pas la peine d'envoyer leurs enfants à l'internat ils y seront mal et de toute manière ils n'y recevront aucune instruction sérieuse. J'ai rencontré cette situation dans la région du gisement de $\mathrm{Tjan}^{4}$ dans la deuxième moitié des années 1990.

Parfois, la protestation se manifeste sous forme de silence des enfants venus des campements quand ils sont à l'internat ou à l'école. C'est d'ailleurs sur cette base que les enseignants envoient parfois ces enfants dans les écoles pour enfants intellectuellement peu développés, au lieu de travailler avec eux de manière plus attentive et professionnelle. En discutant avec les étudiants de l'Université d'Ougrie, à Hanty-Mansijsk, beaucoup d'entre eux m'ont dit que les pires souvenirs qu'ils gardaient des premiers jours d'école étaient que « l'institutrice criait ».

29 Le silence joue un rôle important dans l'adaptation communicative. Par exemple, les Apaches restent silencieux dans des situations où quelqu'un se met en colère, exprime de la fureur. Dans une telle situation, la tradition prescrit le silence (Basso 1970). Les autochtones du nord de la Russie eux aussi utilisent une tactique de comportement semblable avec les industriels et les travailleurs du pétrole. Lors de la signature des accords économiques, les compagnies organisent des réunions, où elles rassemblent tous les Khantys et les Nénetses des campements et leur expliquent les conditions de signature des accords et leur contenu. Au cours de la deuxième moitié des années 1990, il est souvent apparu lors de telles réunions que toutes les conditions n'étaient pas remplies, mais les autochtones gardaient le silence. Mais ce n'était pas un silence de défaite, comme il aurait pu paraitre de prime abord. Ils se taisaient et attendaient, ils reculaient, car ils croyaient que les industriels s'en iraient ou qu'ils estimaient qu'ils pourraient obtenir ce qui avait été promis, car «ils s'étaient regardés dans les yeux ", ce qui, d'après leur droit coutumier, était suffisant. Ce type de silence d'attente a fait l'objet de commentaires dans les écrits d'E. Esterberg, spécialiste des sagas islandaises. Elle fait remarquer que dans de telles situations, les gens dans les sagas restent silencieux, dans la mesure où toute parole pourrait seulement approfondir la situation 
de confrontation qui s'était créée. Le silence est une étape intermédiaire sur le chemin qui va d'un acte à l'autre, ce n'est aucunement l'étape finale. La chercheuse rattache ce silence expectatif, très chargé, au modèle de culture "à régime unique " (Esterberg 1996, p. 35). Nous trouvons une autre réflexion sur le silence et sur la parole dans les sagas chez A.Ja. Gurevič, qui pense qu'elles sont des sources possibles et des éléments régulateurs de la mentalité judiciaire, dans la mesure où dans les sagas les sujets traitant de résolutions judiciaires sont fort répandus. La personne s'y voit comme de l'extérieur, dans la mesure où elle dépend de la décision du groupe social (Gurevič 1996). Chez les autochtones de Russie le silence vis-à-vis des industriels du pétrole est une tentative d'établir le contact par le silence, de donner à leur interlocuteur la possibilité de se sentir participant. La complication et le danger de cette tactique tiennent au fait que les industriels (d'ailleurs comme les fonctionnaires) l'interprètent de manière bien plus univoque.

Dans la culture autochtone, il existe des symboles sémantiquement forts, à l'aide desquels on peut transmettre des informations non seulement au sein de la communauté, mais aussi vers l'extérieur. Il est possible que les autochtones eux-mêmes ne réfléchissent pas forcément à la raison pour laquelle aujourd'hui ils utilisent tel ou tel élément de leur culture. Cela leur vient naturellement : incluant la lutte politique dans leur vie, c'est-à-dire dans leur culture, ils lui donnent des formes signifiantes dans le cadre de leur mode de vie. Dans leur culture, l'acte est plus souvent utilisé que la parole. Par exemple pour exprimer des revendications vis-à-vis des compagnies pétrolières, dans les années 1990, les autochtones, sans paroles superflues, ont monté un čum en ville. Lors de l'une de ces manifestations organisées par le poète et éleveur de rennes Jurij Vella, dans l'okrug de Khanty-Mansijsk, au début des années 1990, on a vu clairement la ritualisation de la culture politique contemporaine des peuples du Nord ${ }^{5}$. Les Nénetses ont un rituel d'après lequel si une personne meurt dans un čum, on pouvait l'y laisser, en tournant l'entrée du čum du « côté de la nuit ». Ainsi le čum était transformé en tombeau. Ainsi J. Vella décida de s'appuyer sur ce rituel lors de cette manifestation.

31 Le čum fut monté devant le bâtiment de l'administration. Il s'y trouvait un mannequin représentant l'administration. Sur la tente, un écriteau: "Attention! Malade à l'intérieur! Parlez doucement!». Sur le mannequin, un tract disait: «diagnostic approximatif : peste pétrolière ? Diagnostic définitif - » C'était à l'administration même de l'okrug de le déterminer (notes de terrain; voir aussi Gluhih 1995). Avant même la manifestation, quand J. Vella avait annoncé son idée, il avait dit :

Si l'administration parle avec nous et accepte de ne pas toucher à nos terres, nous aurons compris que l'administration est guérie, et nous retirerons ce čum. Sinon, nous considèrerons que la malade est décédée, et nous laisserons le čum sur la place, en le retournant du côté de la nuit. Pour nous, les autochtones, notre administration a attrapé une grave maladie contagieuse et en est morte.

Cette action n'a réussi à interrompre la vente des gisements que pour peu de temps. La théâtralité de la manifestation a certes attiré l'attention générale, mais elle a aussi témoigné de la quête de compromis avec le pouvoir et avec les industriels du pétrole, mise en œuvre par des autochtones. Car le but de cette lutte n'était pas d'obtenir la restitution de la terre et l'arrêt de l'extraction du pétrole, comme on pourrait le croire de prime abord, mais de garder les frontières existant à ce moment-là entre les territoires d'exploitation industrielle et ceux d'exploitation traditionnelle. La lutte politique des autochtones prend la forme de manifestations, mais elle n'est pas 
agressive. Leur action ne suscite pas de réactions, ils ne sont ni compris ni acceptés, mais ils continuent à s'exprimer publiquement.

Les éléments principaux de la culture politique syncrétique des peuples autochtones du Nord, telle qu'elle est en train de se former sont d'une part la présentation de "leur " culture par le truchement des outils de la culture de la population «immigrée » et d'autre part l'inclusion du système politique du pays dans leur propre vision du monde. Ce processus est en train de se dérouler sous nos yeux, ce qui en rend l'interprétation compliquée. D'autant qu'en étudiant la culture politique, nous sommes confrontés plutôt à des interprétations d'interprétations, «nous devons deviner des significations, apprécier nos intuitions, et tirer des conclusions explicatives de nos trouvailles les plus réussies ", d'après ce que dit C. Geertz (Geertz 2004, p. 28), qui dans ce travail sont construites sur la mise en rapport des déclarations et des actes aussi bien de la part des autochtones que du pouvoir d'État et des entreprises privées, lesquels leur sont souvent opposés. Et si les mécanismes d'établissement d'un dialogue entre l'État et la société, dont les autochtones font partie, nous sont connus, la culture politique autochtone n'a fait l'objet que de peu d'études. Elle est vue comme "une action expressive», qui comprend des symboles standardisés et uniques (Lič 2001, p. 18-19).

L'utilisation du rituel et d'un comportement ritualisé dans le cadre de conflits touchant à l'utilisation de la terre tient au désir des autochtones d'être écoutés, de porter jusqu'aux autorités leurs revendications dans des conditions où les méthodes juridiques ordinaires ne sont guère efficaces. Le rituel permet de tenter d'inclure dans l'univers autochtone des participants qui n'en font pas traditionnellement partie (le président, l'administration).

Le čum sur la place centrale de la ville est un rituel minimum. De nos jours, tous les autochtones, et de loin, ne vivent pas dans des čum, ni même ne s'en servent comme habitation temporaire. Mais le čum a joué un rôle central dans la culture traditionnelle des éleveurs de rennes et, avec le renne, il en est l'emblème. Tout ici est significatif : lieu d'habitation, le čum reflète le mode de vie. Non seulement il est le logement le plus adapté aux conditions naturelles du Nord, mais il permet d'identifier jusqu'au statut social des gens qui y vivent ainsi que leurs représentations mythologiques; une étude plus approfondie montre qu'il représente le modèle du monde tel qu'il vit dans cette société. En ville, le čum de par sa forme et de par les matériaux dont il est fait (des peaux de rennes) est vu comme une marque d'une culture autochtone, étrangère, alternative même pour ceux qui ne se livreront pas à l'analyse des finesses sémiotiques. Les autochtones incluent naturellement leur combat politique dans leur vie et lui donnent, comme je l'ai dit, des formes qui pour eux ont du sens. C'est pourquoi J. Vella a choisi une forme de la manifestation qui est organique pour sa culture. Dans ce cas, le čum ne représente pas seulement la confrontation, il est aussi une tentative d'établir un dialogue : ainsi les autochtones domestiquent à leur manière l'espace, nouveau pour eux, de la ville, de la culture officielle.

Une démarche analogue a été étudiée dans le détail par V. Turner qui prend l'exemple du rapport au business en Afrique. Il écrit :

Dans une société fondée sur la parenté, on peut faire deux choses avec le monde des affaires. On peut dire, comme le petit garçon qui voit pour la première fois une girafe, "Je n'y crois pas ", et refuser l'existence sociale de ce fait biologique; ou bien, acceptant ce fait, on peut essayer d'en tenir compte. Si on essaye d'en tenir compte, il faut, pour autant que ce soit possible, le présenter comme non contradictoire avec l'ensemble de la culture (Turner 1983, p. 140). 
Pour faire face au conflit qui a émergé dans la culture traditionnelle, on peut adopter deux tactiques différentes de comportement rituel: "soit on déracine l'élément étranger de son univers, soit on le domestique» (Bajburin 1993, p 191). Pour les Khantys et les Nénetses des forêts le čum, comme on l'a évoqué, en tant que domicile temporaire, devient un abri dans les déplacements forcés, quand l'industrie du pétrole conquiert de plus en plus terres nouvelles. Le manque de pâturage oblige les autochtones de l'okrug autonome de Hanty-Mansijsk à limiter leurs migrations ; mais j'ai pu voir, chez des Nénetses des forêts, des huttes en rondins aménagées à l'intérieur comme des čum. Peut-être qu'avec le temps, le čum acquerra encore de nouvelles fonctions, mais comme moyen et espace de combat il est employé par les autochtones dans d'autres pays aussi, comme le montre l'expérience des Sames de Norvège.

\section{Le silence comme code de compréhension}

Les autochtones du Nord peuvent communiquer sans paroles. Ce n'est pas facile d'avoir l'explication de ce phénomène ; on peut en trouver une dans un travail d'A.S. Pesikova, qui parle de l'existence d'une "auréole" pour chaque objet ou phénomène, qui enregistre l'effet des autres objets (Pesikova 1996, p. 132). C'est peut-être effectivement cela qui permet aux Khantys de transmettre des informations sans faire appel à la parole, d'accomplir des actes en pensée. D'ailleurs il y a des lieux sacrés dont non seulement il ne faut pas parler, mais qu'il ne faut pas regarder. En même temps, ceci se rapporte à des pratiques quotidiennes, comme à l'élevage des rennes (faire paître ses rennes en pensée).

Pourquoi aujourd'hui les autochtones ne veulent pas faire connaître toutes leurs connaissances sur le monde environnant et sur les lieux sacrés, qui en font partie intégrante ? Vraisemblablement, ils ont tiré enseignement de la triste expérience des débuts de l'exploitation industrielle du Nord, quand de nombreux monuments ont été détruits. Les autres peuples autochtones du monde sont passés par ce même calvaire, en particulier aux USA.

J'ai discuté du sort du développement des cultures traditionnelles avec l'écrivain américain N. Scott Momaday, lors de sa visite à Moscou en 2000. Il m'a dit que

dans l'histoire des Indiens il y a des exemples où leurs idées sont parties vers

l'extérieur et où il n'en est ressorti que du mal. C'est peut-être là une raison qui explique que certaines tribus ne veulent pas de culture écrite. On connaît un exemple dans le sud-ouest des USA où une institutrice au cours d'une leçon à l'école du village a écrit au tableau un mot dans la langue de la tribu; le chef a parlé avec elle et lui a interdit d'écrire les mots de leur langue." Il pense que "pour cette raison les Indiens écrivains écrivent en anglais et qu'il n'y a pas de tradition de culture écrite.

41 K. Basso décrit les formes de silence chez les Apaches : les enfants rentrent à la maison après l'internat, et les parents les premiers temps ne parlent pas du tout avec eux. Ses informateurs lui ont expliqué la situation de la sorte :

À l'internat, les enfants communiquent avec des Blancs, et sont sous l'influence de leurs pensées et de leurs valeurs. Ils oublient, et ils ont honte de ce que leurs parents sont pauvres. Ils oublient qu'ils sont apaches. Nous ne leur disons rien. Ils ont passé beaucoup de temps loin de la maison, et nous ne savons pas comment ils se sentent. Au bout d'un temps, nous voyons qu'ils aiment être là. Cela veut dire que 
nous aussi nous pouvons nous sentir bien. Donc nous pouvons recommencer à

parler avec eux. Tout est rétabli comme c'était avant leur départ (Basso 1970). bouleversement de l'ordre en se taisant. On peut sans doute dire que les gens par le silence, en l'utilisant comme un instrument, travaillent sur la situation et rétablissent l'ordre bouleversé.

Bien que la politique actuelle envers les peuples du Nord ait été mise en œuvre depuis des décennies, nous avons l'impression que les aspirations réelles des autochtones à maintenir et développer le mode de vie traditionnel n'ont toujours pas été comprises du pouvoir. Ils montrent au monde par divers moyens une réalité compliquée : que dans le Nord sont représentées diverses cultures et que l'État et la société doivent apprendre à gérer cette diversité. Les populations autochtones utilisent pour ce faire les normes et les mécanismes de leur culture traditionnelle. La parole et le silence n'en sont pas les seuls marqueurs, mais ce sont les plus clairs, et ils sont importants pour pouvoir l'interpréter scientifiquement. Les autochtones s'efforcent d'établir des relations de partenariat et obtenir leur acceptation par l'État et par les entreprises industrielles, montrant ainsi que dans le Nord, malgré l'immensité du territoire, il existe des liens très étroits entre les gens ainsi qu'entre les gens et la nature. Mes matériaux de terrain me montrent que les autochtones apprécient beaucoup la capacité à se taire, à se comporter correctement dans le dialogue, sans rien dire de superflu. Un tel comportement présuppose non seulement l'empathie de l'interlocuteur, mais aussi qu'il assume toute responsabilité pour ses actes et ses paroles.

\section{BIBLIOGRAPHIE}

BAJBURIN Albert 1993 = БАЙБУРИН АЛЬБЕРТ КАШФУЛЛОВИЧ, РИТУАЛ В ТРАДИЦИОННОЙ КУЛЬТУРЕ (le Rituel dans la culture traditionnelle), САНКТ-ПЕТЕРБУРГ.

BASSO Keith H., 1970, “'To Give up on Words': Silence in Western Apache Culture”, Southwestern Journal of Anthropology, ${ }^{\circ}$ 26, p. 213-230.

BUTOVSKAJA Marina 2004 = БУТОВСКАЯ МАРИНА ЛЬВОВНА, ЯЗЫК ТЕЛА: ПРИРОДА И КУЛЬТУРА (la Langue du corps : nature et culture), МОсКВА.

ESTERBERG EVa 1996 = ЭСТЕРБЕРГ ЭВА, «МОЛЧАНИЕ КАК СТРАТЕГИЯ ПОВЕДЕНИЯ. СОЦИАЛЬНОЕ ОКРУЖЕНИЕ И МЕНТАЛЬНОСТЬ В ИСЛАНДСКИХ САГАХ » (le Silence en tant que stratégie de comportement. Environnement social et mentalité dans les sagas islandaises), Arbor Mundi. МИРОВОЕ ДЕРЕВО, $\mathrm{n}^{\circ} 4$, p. 21-42

GEERTZ Clifford 2004 = ГИРЦ К., ИНТЕРПРЕТАЦИЯ КУЛЬТУР (l'Interprétation des cultures), МОСКВА. GLUHIH Albina 1995 = ГЛУХИХ АЛЬБИНА СЕРГЕЕВНА, «ЛЕНИН ТОЖЕ ОТВЕРНУЛСЯ» (Lénine aussi s'est détourné), Новости югры (Nouvelles de l'Ougrie), 11.05.1995. 
GOLOVNËV Andrej 1995 = ГОЛОВНЕВ АНДРЕЙ ВЛАДИМИРОВИЧ, ГОВОРЯЩИЕ КУЛЬТУРЫ: ТРАДИЦИИ САмОДИЙЦЕВ И УГРОВ (Cultures parlantes : les traditions des Samoyèdes et des Ougriens), ЕКАТЕРИНБУРГ.

GUREVIČ ArOn 1996 = ГУРЕВИЧ АРОН ЯКОВЛЕВИЧ, «НЕСКОЛЬКО СООБРАЖЕНИЙ НА ПОЛЯХ СТАТЬИ ЭВЫ ЭСТЕРБЕРГ» (Quelques réflexions sur le champ de l'article d'Eva Esterberg), Arbor Mundi. МИРОВОЕ ДЕРЕВО, $\mathrm{n}^{\circ} 4,43-46$

HRISTOFOROVA Olga 1998 = ХРИСТОФОРОВА ОЛЬГА БОРИСОВНА, «ОСОБЕННОСТИ КОММУНИКАТИВНОГО ПОВЕДЕНИЯ НАРОДОВ СИБИРИ И ИХ РОЛЬ В МЕЖКУЛЬТУРНОМ ОБЩЕНИИ» (les Particularités du comportement de communication des peuples de Sibérie et leur rôle dans le dialogue interculturel), in ОТВ. РЕД. Н.В. УФИМЦЕВА, ЯЗЫКОВОЕ СОЗНАНИЕ: ФОРМИРОВАНИЕ И ФУНКцИониРОВАНИЕ (Conscience linguistique : formation et fonctionnement), москВА, 224-231.

HRISTOFOROVA Olga 2006 = ХРИСТОФОРОВА ОЛЬГА БОРИСОВНА, « ИНТЕРПРЕТАЦИИ МОЛЧАНИЯ: РЕЧЕВОЙ ЭТИКЕТ НАРОДОВ СЕВЕРА В ЗАМЕТКАХ ПУТЕШЕСТВЕННИКОВ И ПО ДАННЫМ ФольклорА » (l'Interprétation du silence : l'étiquette du discours chez les peuples du Nord dans les observations des voyageurs et dans les données du folklore), Arbor mundi. МЕЖДУНАРОДНЫЙ ЖУРНАЛ ПО ТЕОРИИ И ИСТОРИИ МИРОВОЙ КУЛЬТУРЫ, ВЫП. ${ }^{\circ}$ 12, p. 82-194.

IVANOv Sergej 1975 = ИВАНОВ СЕРГЕЙ ВАСИЛЬЕВИЧ, «ДРЕВНИЕ ПРЕДСТАВЛЕНИЯ НЕКОТОРЫХ НАРОДОВ СИБИРИ О СЛОВЕ, МЫСЛИ И ОБРАЗЕ» (les Anciennes représentations de quelques peuples de Sibérie sur la parole, la pensée et la forme), СТРАНЫ И НАРОДЫ ВОСТОКА, ВЫП. XVII. кн. 3, М., p. 119-126.

JENNESS Diamond, 1923, The Life of The Copper Eskimo, Ottawa

KREJNDLIN Grigorij 2005 = КРЕЙДЛИН ГРИГОРИЙ ЕФИМОВИЧ, МУЖЧИНЫ И ЖЕНЩИНЫ В

НЕВЕРБАЛЬНОЙ КОММУНИКАЦИИ (les Hommes et les femmes dans la communication non verbale), МОСКВА.

LAPINA Majna 1998 = ЛАПИНА МАЙНА АФАНАСЬЕВА, ЭТИКЕТ ХАНТОВ (l'Étiquette chez les Khantys), тОМск.

LEACH Edmund 2001 = ЛИЧ Э., КУЛЬТУРА И КОММУНИКАЦИЯ. ЛОГИКА ВЗАИМОСВЯЗИ СИМВОЛОВ (Culture and communication: the logic by which symbols are connected), МосквА, p. 18-19. NOVIKOVA Natalja 1995 = НОВИКОВА НАТАЛЬЯ ИВАНОВАЬНА, ТРАДИЦИОННЫЕ ПРАЗДНИКИ МАНСИ (les Fêtes traditionnelles mansi), москВА.

NOVIKOVA Natalja 2007 = НОВИКОВА НАТАЛЬЯ ИВАНОВАЬНА, «ИНСТИТУТЫ ПРАВОСУДИЯ: ПУТИ ВОССТАНОВЛЕНИЯ СПРАВЕДЛИВОСТИ НА СЕВЕРЕ КАНАДЫ» (Les institutions de la justice : les voies du rétablissement de la justice au nord du Canada), РАСЫ И НАРОДЫ, ЕЖЕГОДНИК. 33, МОСКВА, p. 111-128.

PESIKOVA Agrafena 1996 = ПЕСИКОВА АРАФЕНА СЕМЕНОВНА, «СОВРЕМЕННАЯ СТРУКТУРА МИРОПОНИМАНИЯ ОБСКИХ УГРОВ, ВЕДУЩИХ ТРАДИЦИОННЫЙ ОБРАЗ ЖИЗНИ (НА ПРИМЕРЕ сургУтских ХАнты) » (la Structure actuelle de la compréhension du monde des Ougriens de l'Ob' qui suivent le mode de vie traditionnel sur la base de l'exemple des Khantys de Surgut), пАмЯтники югры (les Monuments de l'Ougrie), томск.

PESIKOVA Agrafena 1996b = ПЕСИКОВА АРАФЕНА СЕМЕНОВНА, «НЕКОТОРЫЕ АСПЕКТЫ ЭТНОПСИХОЛОГИИ ОБСКИХ УГРОВ (НА ПРИМЕРЕ ПИМскИХ ХАНТЫ) » (Quelques aspects de la psychologie ethnique des Ougriens de l'Ob' sur la base de l'exemple des Khantys du Pim), 
НАУЧНЫЕ ТРУДЫ СУРГУТСКОГО УНИВЕРСИТЕТА (Travaux scientifiques de l'Université de Surgut), СУРГУТ, тОм. 3.

POPOV Andrej 1959 = ПОПОВ АНАРЕЙ АЛЕКСАНДРОВИЧ, «ПЕРЕЖИТКИ ДРЕВНИХ ДОРЕЛИГИОЗНЫХ ВОЗЗРЕНИЙ ДОЛГАНОВ НА ПРИРОДУ „ (Les survivances des anciennes conceptions préreligieuses des Dolganes sur la nature), СОВЕТСКАЯ ЭТНОГРАФИЯ (Еthnographie soviétique), $\mathrm{n}^{\circ} 2$.

PRANIS Kay, STEWART Barry, WEDGE Mark 2010 = ПРАНИС К., СТЮАРТ Б., УЕДЖ М., КРУГИ ПРИМИРЕНИЯ. ОТ ПРЕСТУПЛЕНИЯ К СООБЩЕСТВУ, (Peacemaking Circles. From Conflict to Community), ПЕР. С АНГЛ., МОСКВА, p. 94-103.

PUŠKARËVA Elena 2002 = ПУШКАРЕВА ЕЛЕНА ТИМОФЕЕВНА, «ОБРАЗЫ СЛОВА В ФОЛЬКЛОРЕ НЕНЦЕВ» (les Formes du mot dans le folklore des Nénetses), ЭТНОГРАФИЧЕСКОЕ ОБОЗРЕНИЕ (Revue ethnographique), $\mathrm{n}^{\circ} 4$, p. 28-38.

PUŠKARËVA Elena 2007 = ПУШКАРЕВА ЕЛЕНА ТИМОФЕЕВНА, КАРТИНА МИРА В ФОЛЬКЛОРЕ НЕНЦЕВ: СИСТЕМНО-ФЕНОМЕНОЛОГИЧЕСКИЙ АНАЛИЗ (la Vision du monde dans le folklore des Nénetses : analyse systémo-phénomènologique), ЕКАТЕРИНБУРГ

TURNER Victor 1983 = ТЭРНЕР В., СИМВОЛ И РИТУАЛ (Symbole et rituel), MOСКВА.

\section{NOTES}

1. Pour plus de détails, voir Novikova 2007.

2. Archives : ГОСУДАРСТВЕННЫЙ АРХИВ ХАНТЫ-МАНСИЙСКОГО АВТОНОМНОГО ОКРУГА, Ф.138, оП.1, Д.18, л. 2-5.

3. Appellation des tentes coniques utilisée dans le nord de la Russie.

4. En russe : ТЯНСКОЕ МЕСТОРОЖДЕНИЕ (Gisement sis dans le raïon de Surgut).

5. Voir Leete 2013.

\section{RÉSUMÉS}

Le discours et le silence sont des traits indissolubles dans le monde des peuples autochtones du Nord. C'est bien dans l'idée de leur donner le droit à la parole dans le système juridique du pays qu'a été adoptée en Russie la législation les concernant. Autrement, de la part des organes de l'État, leurs aspirations et leurs intérêts relevaient du champ du silence. Cet article examine les garanties du droit au silence dans le droit international et dans le droit coutumier des peuples autochtones ainsi que dans la pratique judiciaire russe. Il analyse les moyens de non verbaux de transmission de messages dans la culture quotidienne des autochtones, dans leurs relations avec les fonctionnaires et les industriels du pétrole, mais aussi le silence en tant que moyen de protestation dans une société pluriculturelle. Nous interprétons ainsi le silence comme un code de compréhension de la culture autochtone, un moyen de rétablir l'ordre et le dialogue dans le monde contemporain. 
РЕЧЬ И МОЛЧАНИЕ ВЫСТУПАЮТ НЕРАЗРЫВНЫМИ ХАРАКТЕРИСТИКАМИ МИРА КОРЕННЫХ НАРОДОВ СЕВЕРА. ИМЕННО С ЦЕЛЬЮ ДАТЬ АБОРИГЕНАМ ПРАВО ГОЛОСА В ГОСУДАРСТВЕННОЙ ПРАВОВОЙ СИСТЕМЕ И БЫЛИ ПРИНЯТО ПОСВЯЩЕННОЕ ИМ ЗАКОНОДАТЕЛЬСТВО В РОССИИ. БЕЗ ЭТОГО ИХ ЧАЯНИЯ И ИНТЕРЕСЫ ОТНОСИЛИСЬ К СФЕРЕ МОЛЧАНИЯ СО СТОРОНЫ ГОСУДАРСТВЕННЫХ ОРГАНОВ. В СТАТЬЕ РАССМАТРИВАЮТСЯ ГАРАНТИИ ПРАВА НА МОЛЧАНИЕ В МЕЖДУНАРОДНОМ И ОБЫЧНОМ ПРАВЕ КОРЕННЫХ НАРОДОВ, В РОССИЙСКОЙ СУДЕБНОЙ ПРАКТИКЕ. АНАЛИЗИРУЮТСЯ НЕВЕРБАЛЬНЫЕ СРЕДСТВА ПЕРЕДАЧИ ИНФОРМАЦИИ В АБОРИГЕННОЙ БЫТОВОЙ КУЛЬТУРЕ, ПРИ ИХ ОБЩЕНИИ С ЧИНОВНИКАМИ И НЕФТЯНИКАМИ, А ТАКЖЕ МОЛЧАНИЕ СРЕДСТВО ПРОТЕСТА В УСЛОВИЯХ МНОГОКУЛЬТУРНОГО ОБЩЕСТВА. В РЕЗУЛЬТАТЕ МОЛЧАНИЕ ИНТЕРПРЕТИРУЕТСЯ КАК КОД ПОНИМАНИЯ АБОРИГЕННОЙ КУЛЬТУРЫ, СРЕДСТВО ВОССТАНОВЛЕНИЯ ПОРЯДКА И ДИАЛОГА В СОВРЕМЕННОМ МИРЕ.

Speech and silence are two indissolubly linked features in the world of the native peoples of the North. In Russia's legal system the legislation concerning this segment of the population is aimed at allowing their speech to have weight. Otherwise, their aims and their interests have remained, for state institutions, in the sphere of silence. This article examines how the right to silence is guaranteed by international law and the native people's customary law, as well as in Russians judicial practice. It analyses non-verbal means of message transmission in the natives' everyday culture, in their relationship to civil servants and oil drillers, but also silence as protest in a multicultural society. Thus, we interpret silence as a comprehension code of native culture and as a way to restore order and dialogue in the contemporary world. 